LETTER TO JMG

\title{
Inadvertent diagnosis of male infertility through genealogical DNA testing
}

\author{
T E King, E Bosch*, S M Adams, E J Parkin, Z H Rosser, \\ $M$ A Jobling
}

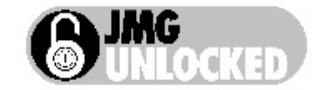

This article is available free on JMG online via the JMG Unlocked open access trial, funded by the Joint Information Systems Committee. For further information, see http://img.bmijournals.com/cgi/content/ full $/ 42 / 2 / 97$
T he potentially informative relationship between Y chromosomes and patrilinearly inherited surnames ${ }^{1}$ has led to a major expansion in the number of commercial companies offering $\mathrm{Y}$ chromosomal DNA polymorphism analysis to members of the public; because of the geographical specificity of Y chromosomal types, ${ }^{2}$ many companies also offer to deduce "ancestry". As the number of markers used in these tests increases, so does the probability of inadvertently diagnosing male infertility through the detection of Y chromosomal deletions. Using commercially typed Y markers, we here report the ascertainment of such deletions in general population samples.

\section{METHODS}

Samples were collected with informed consent and relevant ethical approval from the Leicestershire Research Ethics Committee (ref. 5796) and the Committee for Scientific Investigations in Greenland (ref. 505-16).

Deletion analysis was carried out using standard PCR techniques; primer sequences and conditions are given in original references cited for markers in the text below.

\section{RESULTS}

As part of a Y chromosomal haplotyping study of 2574 English males ascertained on the basis of surname and geographical origin, we included the binary marker PN253 which defines an important haplogroup, Rlb, common in Western Europe. ${ }^{4}$ The PN25 polymorphism is an A to C transversion in one of three copies of the PN25 sequence, which lie in the three ampliconic repeat units gl, g2, and $\mathrm{g} 3^{5}$ of the $A Z F C$ region on Yq (fig $1 \mathrm{~A}$ ). In three unrelated males PN25 sequences were absent, and analysis of markers across the $A Z F C$ region showed a pattern of presence or absence consistent with these males carrying $\sim 3 \mathrm{Mb}$ deletions caused by non-allelic homologous recombination (NAHR) between the b2 and b4 repeats, previously observed in 47 of 48 infertile $A Z F C$ deletion patients.

In a population study of 69 Greenlandic Inuit males, ${ }^{9}$ we typed a set of 19 Y-specific microsatellites and a number of binary markers on the Y chromosome. In one male nine of 19 microsatellites and a single binary marker, M173, failed to amplify (fig 1B). Since all of these markers lie in the AZFa region on $\mathrm{Yq}$, this is consistent with this male carrying an $A Z F a$ deletion. Testing of further loci in and around the region confirmed this, and showed that the deletion has arisen through a mechanism observed in the majority of $A Z F a$ cases, ${ }^{7}{ }^{10}{ }^{11}$ that is, by NAHR between directly repeated HERVs $780 \mathrm{~kb}$ apart and flanking the $A Z F a$ region.

\section{DISCUSSION}

$A Z F$ deletions are normally ascertained by testing the DNA of men with idiopathic infertility, and estimates of their frequencies are derived from clinical data. Here, we have ascertained deletions in an unbiased way.

\section{Key points}

- Commercial Y chromosome testing for genealogical purposes is increasing in popularity and is employing an increasing number of polymorphic markers, raising the possibility of the detection of $Y$ chromosomal deletions in clients.

- Here we show that commercially used markers detect $A Z F a$ and $A Z F c$ deletions associated with male infertility in general population samples.

- Companies should avoid markers in the commonly deleted regions of the chromosome, and meanwhile their clients should be warned of the possibility and implications of the inadvertent diagnosis of infertility.

$A Z F c$ deletions are the commonest of the classes found in infertile men, with a frequency estimated to be 1 in $4000 .{ }^{5}$ We found three deletions in 2574 English males, and can add to these an additional 681 males (mostly from the Iberian peninsula) typed for PN25 in whom we would have expected to detect some deletions had there been any. The frequency we find, three in 3255, is not significantly different from 1 in $4000(\mathrm{p}=0.20$, Fisher exact test $)$.

$A Z F a$ deletions are particularly rare, constituting $1-2 \%$ of all pathogenic Y chromosomal deletions, ${ }^{12}$ and have a likely population frequency of less than 1 in $100000 .{ }^{512}$ We found one deletion in 69 Inuit males, but including 5303 additional undeleted chromosomes from many, mostly Eurasian, populations typed with $A Z F a$ region microsatellites in our laboratory, the observed incidence is one case in 5374. A large database (see Roewer et al ${ }^{13}$ and http://www.yhrd.org) of $\sim 23000$ Y chromosomal microsatellite haplotypes includes DYS389, and contributors would therefore be expected to detect $A Z F a$ deletions, although it is possible that such "incomplete" haplotypes would not be submitted. The database contains no examples with null alleles at this locus. Notably, we have found no examples of $A Z F b$ deletions, intermediate in frequency between $A Z F a$ and $c$ deletions, ${ }^{14}$ in our population studies $(\mathrm{n}=5374)$ : these ${ }^{14}$ would be expected to lack several microsatellites, including the widely typed DYS385 and DYS392.

While the typing of the binary marker PN25, in the AZFC region, is not being offered commercially, at least one major testing company types the highly informative multi-locus microsatellite, DYS464, ${ }^{15}$ lying within the rl-r4 ampliconic repeats, and also absent in the three $A Z F c$ males we have identified (fig lA). Microsatellites within the $A Z F a$ and $b$ regions are typed by all companies carrying out commercial $Y$

Abbreviations: NAHR, non-allelic homologous recombination; STS, sequence-tagged site 


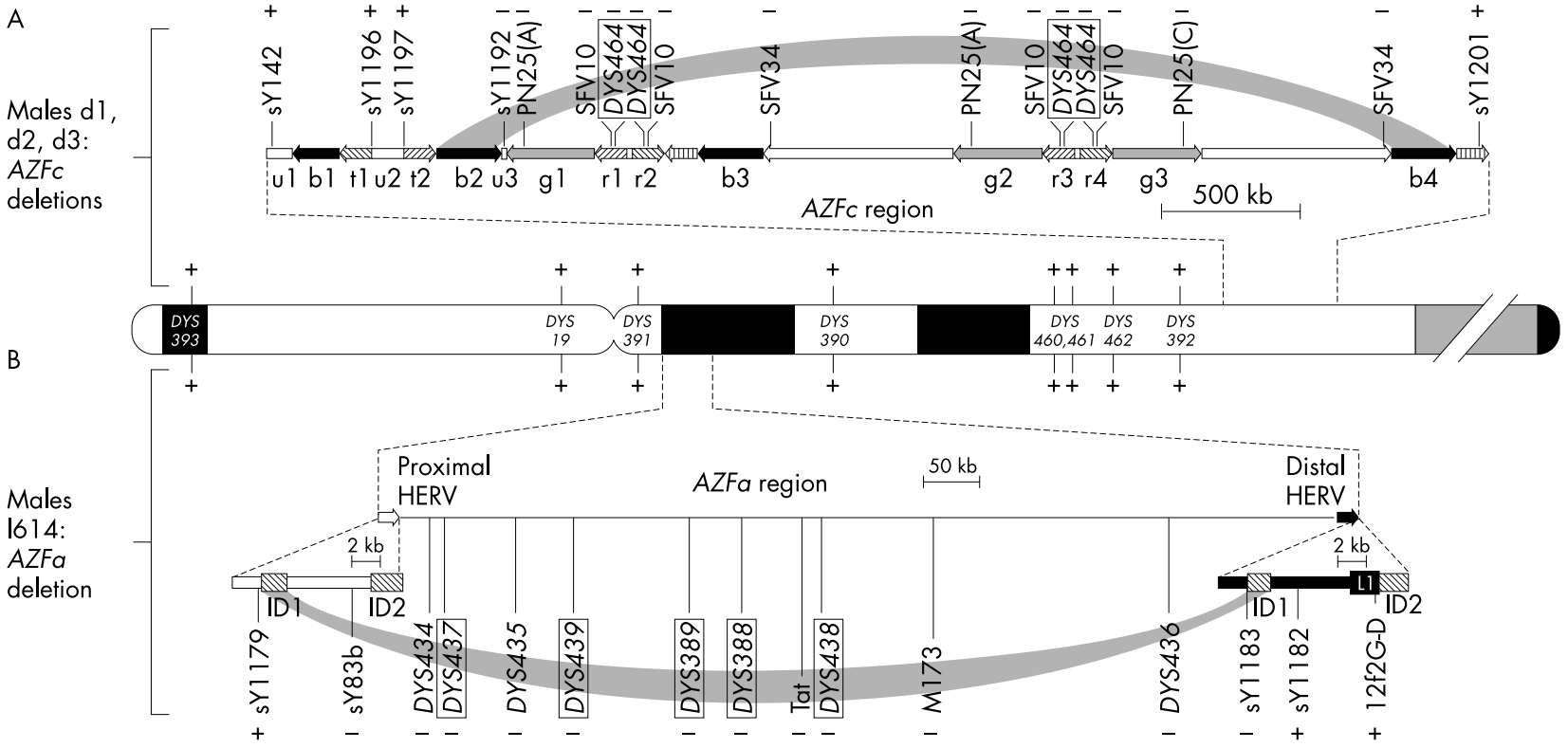

Figure 1 Detection of AZFc and AZFa deletions. The Y chromosome idiogram (centre) shows the approximate positions of the AZFc and AZFa regions and of eight Y-specific microsatellites. ${ }^{6}$ Throughout, " + " indicates marker present, "-" marker absent, and boxes around marker names indicate deleted markers that are typed by commercial companies. (A) Deletion analysis of males $\mathrm{d} 1$, $\mathrm{d} 2$, and $\mathrm{d} 3$. The binary marker PN25 and the microsatellite DYS464 are absent, as are a set of sequence-tagged sites (STSs, prefixed "sY") $)^{5}$ and sequence family variants (prefixed "SFV") ${ }^{5}$ in the region consistent with deletion by NAHR between repeat units b2 and b4 (curved grey bar). (B) Deletion analysis of male 1614. Binary markers M173 and Tat and a set of eight microsatellites (italics) are absent, as are STSs, ${ }^{8}$ consistent with deletion by NAHR between the IDI identity blocks of the flanking human endogenous retroviral sequence (HERVs; curved grey bar). L1 indicates insertion of L1 material into distal HERV.

chromosome testing (fig 1B). Such testing will therefore lead to the detection of $A Z F$ deletions and thus an inadvertent diagnosis of likely infertility (some $A Z F c$ deleted males have been reported to father children $\left.{ }^{16-18}\right)$. Recent identification ${ }^{19}$ of 166 new Y-specific microsatellites brings the total number known to over 200, and with so many to choose from it would be easy to avoid markers within the AZF intervals of the chromosome. There certainly seems no good reason for continued commercial typing of the AZFC marker DYS464, which in any case offers problems of interpretation because of its multilocal nature. Markers within the $A Z F a$ and $b$ regions are so well established, however, that it is unlikely that they will be abandoned-a problem mitigated by the comparative rarity of these classes of deletions. Testing companies routinely inform their customers of the possibility of detecting non-paternities; while they continue to type the current set of markers, they should also warn that these markers are not neutral with respect to fertility.

\section{ACKNOWLEDGEMENTS}

We thank all DNA donors, and Søren Nørby for assistance.

\section{ELECTRONIC-DATABASE INFORMATION}

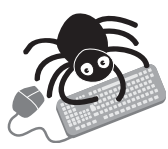

The UंRL of the Y-STR Haplotype Reference Database is http://www.yhrd.org.

\section{Authors' affiliations}

T E King, E Bosch, S M Adams, E J Parkin, Z H Rosser, M A Jobling, Department of Genetics, University of Leicester, University Road, Leicester LE1 7RH, UK

MAJ was supported by a Wellcome Trust Senior Fellowship in Basic Biomedical Science (grant no. 057559), TEK by a Wellcome Prize Studentship (grant no. 061129), and EB, SMA, and ZHR by the Wellcome Trust. EJP was supported by the Arts and Humanities Research
Board within the framework of the European Science Foundation EUROCORES programme "The Origin of Man, Language and Languages".

Competing interests: none declared

${ }^{*}$ Current address: Unitat de Biologia Evolutiva, Facultat de Ciències de la Salut i de la Vida, Universitat Pompeu Fabra, Doctor Aiguader 80, 08003 Barcelona, Catalonia, Spain

Correspondence to: Mark A Jobling, Department of Genetics, University of Leicester, University Road, Leicester LE1 7RH, UK; maj4@leicester.ac. uk

Received 8 June 2004

Revised version received 23 June 2004

\section{REFERENCES}

1 Jobling MA. In the name of the father: surnames and genetics. Trends Genet 2001;17:353-7.

2 Jobling MA, Tyler-Smith C. The human $Y$ chromosome: an evolutionary marker comes of age. Nat Rev Genet 2003:4:598-612.

3 Hammer MF, Redd AJ, Wood ET, Bonner MR, Jarjanazi H, Karafet T, Santachiara-Benerecetti S, Oppenheim A, Jobling MA, Jenkins T, Ostrer H, Bonne-Tamir B. Jewish and Middle Eastern non-Jewish populations share a common pool of Y-chromosome biallelic haplotypes. Proc Natl Acad Sci U S A 2000;97:6769-74.

4 Y Chromosome Consortium. A nomenclature system for the tree of human Ychromosomal binary haplogroups. Genome Res 2002;12:339-48.

5 Kuroda-Kawaguchi T, Skaletsky H, Brown LG, Minx PJ, Cordum HS, Waterston RH, Wilson RK, Silber S, Oates R, Rozen S, Page DC. The AZFc region of the $Y$ chromosome features massive palindromes and uniform recurrent deletions in infertile men. Nat Genet 2001;29:279-86.

6 Bosch E, Lee AC, Calafell F, Arroyo E, Henneman P, de Kniiff P, Jobling MA High resolution $Y$ chromosome typing: 19 STRs amplified in three multiplex reactions. Forensic Sci Int 2002;125:42-51.

7 Sun C, Skaletsky H, Rozen S, Gromoll J, Nieschlag E, Oates R, Page DC. Deletion of azoospermia factor a (AZFa) region of human $Y$ chromosome caused by recombination between HERV15 proviruses. Hum Mol Genet 2000;9:2291-6.

8 Bosch $E$, Jobling MA. Duplications of the AZFa region of the human $Y$ chromosome are mediated by homologous recombination between HERVs and are compatible with male fertility. Hum Mol Genet 2003;12:341-7.

9 Bosch E, Calafell F, Rosser ZH, Norby S, Lynnerup N, Hurles ME, Jobling MA. High level of male-biased Scandinavian admixture in Greenlandic Inuit shown by Y-chromosomal analysis. Hum Genet 2003;1 12:353-63. 
10 Blanco $\mathbf{P}$, Shlumukova M, Sargent CA, Jobling MA, Affara N, Hurles ME. Divergent outcomes of intra-chromosomal recombination on the human $Y$ chromosome: male infertility and recurrent polymorphism. J Med Genet 2000;37:752-8.

11 Kamp C, Hirschmann P, Voss H, Huellen K, Vogt PH. Two long homologous retroviral sequence blocks in proximal Yq1 1 cause AZFa microdeletions as a result of intrachromosomal recombination events. Hum Mol Genet 2000;9:2563-72.

12 Affara NA. The role of the Y chromosome in male infertility. Exp Rev Mol Med 2001;3:1-16.

13 Roewer L, Krawczak M, Willuweit S, Nagy M, Alves C, Amorim A, Anslinger K, Augustin C, Betz A, Bosch E, Cagliá A, Carracedo A, Corach D, Dekairelle AF, Dobosz T, Dupuy BM, Füredi S, Gehrig C, Gusmaõ L, Henke J', Henke $L$, Hidding $M$, Hohoff $C$, Hoste $B$, Jobling MA, Kärgel HJ, de Kniiff $P$, Lessig $R$, Liebeherr $E$, Lorente $M$, Martínez-Jarreta $B$, Nievas $P$, Nowak M Parson W, Pascali VL, Penacino G, Ploski R, Rolf B, Sala A, Schmidt U, Schmitt C, Schneider PM, Szibor R, Teifel-Greding J, Kayser M. Online reference database of $Y$-chromosomal short tandem repeat (STR) haplotypes. Forensic Sci Int 2001;118:103-11.
14 Repping S, Skaletsky H, Lange J, Silber S, Van Der Veen F, Oates RD, Page DC, Rozen S. Recombination between palindromes P5 and P1 on the human $Y$ chromosome causes massive deletions and spermatogenic failure. Am J Hum Genet 2002;71:906-22.

15 Redd AJ Agellon AB, Kearney VA, Contreras VA, Karafet T, Park H, de Knijff $P$, Butler JM, Hammer MF. Forensic value of 14 novel STRs on the human Y chromosome. Forensic Sci Int 2002;130:97-111.

16 Chang PL, Sauer MV, Brown S. Y chromosome microdeletion in a father and his four infertile sons. Hum Reprod 1999;14:2689-694.

17 Gatta V, Stuppia L, Calabrese G, Morizio E, Guanciali-Franchi P, Palka G. A new case of $Y q$ microdeletion transmitted from a normal father to two infertile sons. J Med Genet 2002;39:e27.

18 Kühnert B, Gromoll J, Kostova E, Tschanter P, Luetjens CM, Simoni M, Nieschlag E. Case report: natural transmission of an AZFc Y-chromosomal microdeletion from father to his sons. Hum Reprod 2004:19:886-8.

19 Kayser M, Kittler R, Erler A, Hedman M, Lee AC, Mohyuddin A, Mehdi SQ, Rosser Z, Stoneking M, Jobling MA, Sajantila A, Tyler-Smith C. A comprehensive survey of human Y-chromosomal microsatellites. Am J Hum Genet 2004;74:1183-97.

\section{Clinical Evidence-Call for contributors}

Clinical Evidence is a regularly updated evidence-based journal available worldwide both as a paper version and on the internet. Clinical Evidence needs to recruit a number of new contributors. Contributors are healthcare professionals or epidemiologists with experience in evidence-based medicine and the ability to write in a concise and structured way.

Areas for which we are currently seeking authors:

- Child health: nocturnal enuresis

- Eye disorders: bacterial conjunctivitis

- Male health: prostate cancer (metastatic)

- Women's health: pre-menstrual syndrome; pyelonephritis in non-pregnant women

However, we are always looking for others, so do not let this list discourage you.

Being a contributor involves:

- Selecting from a validated, screened search (performed by in-house Information Specialists) epidemiologically sound studies for inclusion.

- Documenting your decisions about which studies to include on an inclusion and exclusion form, which we keep on file.

- Writing the text to a highly structured template (about 1500-3000 words), using evidence from the final studies chosen, within 8-10 weeks of receiving the literature search.

- Working with Clinical Evidence editors to ensure that the final text meets epidemiological and style standards.

- Updating the text every six months using any new, sound evidence that becomes available. The Clinical Evidence in-house team will conduct the searches for contributors; your task is simply to filter out high quality studies and incorporate them in the existing text.

- To expand the topic to include a new question about once every 12-18 months.

If you would like to become a contributor for Clinical Evidence or require more information about what this involves please send your contact details and a copy of your CV, clearly stating the clinical area you are interested in, to Klara Brunnhuber (kbrunnhuber@ bmigroup.com).

\section{Call for peer reviewers}

Clinical Evidence also needs to recruit a number of new peer reviewers specifically with an interest in the clinical areas stated above, and also others related to general practice. Peer reviewers are healthcare professionals or epidemiologists with experience in evidence-based medicine. As a peer reviewer you would be asked for your views on the clinical relevance, validity, and accessibility of specific topics within the journal, and their usefulness to the intended audience (international generalists and healthcare professionals, possibly with limited statistical knowledge). Topics are usually 1500-3000 words in length and we would ask you to review between 2-5 topics per year. The peer review process takes place throughout the year, and our turnaround time for each review is ideally 10-14 days.

If you are interested in becoming a peer reviewer for Clinical Evidence, please complete the peer review questionnaire at www.clinicalevidence.com or contact Klara Brunnhuber (kbrunnhuber@bmigroup.com). 